\title{
Assessment of the Psychosocial Work Environment among Health Care Workers and Its Association with Work and Socioeconomic Status
}

\author{
Mostafa Ghaffari, ${ }^{1,2,3}$ Hassan Alinaghizadeh,,${ }^{1,4}{ }^{*}$ Leila Ghalichi, ${ }^{5}$ Omid Pournik, ${ }^{6}$ and Eva Vingard ${ }^{1}$ \\ ${ }^{1}$ Occupational and Environmental Medicine, Department of Medical Sciences, Uppsala University, Uppsala, Sweden \\ ${ }^{2}$ MD, MPH, PhD, Occupational and Environmental Medicine Department, School of Medicine, Iran University of Medical Sciences, Teheran, Iran \\ ${ }^{3}$ Brain and Spinal Cord Injury Research Center, Neuroscience Institute, Tehran University of Medical Sciences, Tehran Iran. \\ ${ }^{4}$ MSc, PhD Candidate, Senior Statistician, Division of Family Medicine and Primary Care, Department of Neurobiology, Care Sciences and Society, Karolinska Institutet, \\ Stockholm, Sweden \\ ${ }^{5} \mathrm{MD}$, PhD, Epidemiology Department, School of Public Health, Iran University of Medical Sciences, Teheran, Iran \\ ${ }^{6} \mathrm{MD}$, PhD, Community Medicine Department, School of Medicine, Iran University of Medical Sciences, Teheran, Iran \\ ${ }^{7} \mathrm{MD}$, PhD, Occupational and Environmental Medicine, Department of Medical Sciences, Uppsala University, Uppsala, Sweden \\ "Corresponding author: Hassan Alinaghizadeh, Division of Family Medicine and Primary Care, Department of Neurobiology, Care Sciences and Society, Karolinska Institutet, \\ Stockholm, Sweden. Tel: +46-704840374, E-mail: farhad.alinaghizadeh@ki.se
}

Received 2017 May 16; Accepted 2017 July 22.

\begin{abstract}
Background: The health care sector constitutes one of the largest sources of employment worldwide.

Objective: The aim of this study was to describe the psychosocial status of health care workers and its association with different covariates.

Methods: Health care workers from different universities, hospitals, clinics, urban and rural health centers took part in this crosssectional study. The medium version of COPSOQ was used to evaluate the association between COPSOQ and covariates. The multivariate analyses of variance and covariance were employed to determine multivariate and univariate associations between all psychosocial dimensions and covariates.

Results: Most COPSOQ scores showed a good internal consistency and reliability, with total Cronbach's alpha of 0.76 . The study population comprised 7,027 health care workers among whom $64 \%$ were female. The results indicated that nurses are more exposed to the psychosocial work environment compared to the other groups of workers within the health care settings.

Conclusions: Nurses had a significantly higher risk regarding almost all the psychosocial factors. Considering that the main shortage of human resources in our study population belonged to the nursing group, this bad situation is not surprising. Healthcare workers, especially nurses, are facing various psychosocial factors more than other workers are, because all these factors are in the healthcare environment at the same time.
\end{abstract}

\section{Background}

The health care sector constitutes one of the largest sources of employment worldwide $(1,2)$. Based on the world health organization report (3), health care facilities around the world employ over 60 million workers who are exposed to a complex variety of health and safety hazards, from biological hazards to adverse ergonomic and psychosocial factors. In many countries, shortage of health workers now and in the future is a serious concern. For developing countries, this may include migration and brain drain when highly qualified workers move abroad.

Healthcare involves many occupations with varied exposures, including doctors, nurses, midwives, health experts, pharmacists, laboratory technicians, managers, office workers, cooks, catering staff, drivers, and cleaners. In most countries, the majority of the workers are female.

Despite the fact that the health sector has a culture in which health-related surveillance is recognized as important, healthcare workers continue to experience health problems, injuries, and illnesses at the workplace (4-6). Based on one study in the US, about $17.5 \%$ of newly qualified nurses leave within one year of starting their first job (7).

In the last decade, health care researchers have revealed an increase in mental stress for healthcare workers and its short and long term effects on health, sickness absence, sickness presence, low quality of life, motivation, and productivity (8-14).

Sickness in healthcare workers is a concern because many of them continue to work despite mental or other health issues $(15,16)$. This may have an impact on themselves, colleagues, and their patients, in both physical and psychosocial terms $(17,18)$. There is a substantial and growing body of evidence linking the psychosocial working environment to health (19-21).

In the healthcare system in Iran, medical universities are responsible for not only education and research but also for all preventive and curative services in a defined geographical area. The ministry of health and medical educa- 
tion is one of the biggest employers, with around 400,000 persons working in 48 medical universities in the country, and meets all the demands for health care and treatment for more than 75 million inhabitants, with facilities ranging from health centers in small villages to large hospitals in main cities.

The health of health care workers in Iran is an important issue that needs more attention. This study was therefore conducted to generate more information and knowledge about the current health status of Iranian health care workers, with a focus on their psychosocial work environment.

\section{Objectives}

The aim of this study was to describe the psychosocial status of health care workers in Iran and its association with a number of covariates.

\section{Design}

\subsection{Study Design and Sample}

In 2012, a baseline survey was carried out in one of the main medical universities in Iran. The study included health care workers with a regular job contract at different university schools, large hospitals, clinics, urban health centers, and rural health centers. A total of 8,086 health care workers were eligible and invited to participate. They received a questionnaire and a return envelope as well as an information letter about the aim of the study, emphasizing that participation was voluntary.

We collected data about age, sex, education, job-tile, shift work, working hours, income, and workplace as a potential confounder.

\subsection{Measurement of Psychosocial Work Environment}

One of the validated tools for measuring psychosocial occupational exposure is the Copenhagen psychosocial questionnaire (COPSOQ), which was developed by Kristensen and tested in a national survey in Denmark (10). The questionnaire has been developed into three versions (long, medium, and short) and includes in its long version 30 scores of work and health in 141 items (10). This tool has been translated into a number of languages and some comparative studies in various countries have been completed to compare the psychosocial climate of their workplace with that of Denmark $(22,23)$.
To avoid selection bias and measurement bias, we included all health care workers working at the medical university and used the validated Persian version of the Copenhagen psychosocial questionnaire (COPSOQ) (24) to measure the psychosocial work environment. The medium version of the COPSOQ1 consists of 26 scores in 5 dimensions including type of production and task (17 questions), work organization and job content (19 questions), interpersonal relations and leadership (24 questions), work-individual interface (8 questions), and health and well-being (26 questions). Most of the questions have 5 response options: "to a great extent", "to some extent, somewhat, a little, very little" or "always, often, sometimes, rarely, never/almost never". See Table 2 for the content of each score.

\subsection{Statistical Analysis}

Descriptive analysis of centrality was used for all 26 scores in the instrument; mean, standard deviation (SD), and frequencies were presented. The correlation among 26 scores was driven by Person's correlation and a highly significant association among these 26 scores was almost always observed (results not shown).

The original 94 items from COPSOQ were compiled in 26 scores (25) and the reliability of instrument was controlled with Cronbach's alpha. The 5 dimensions (D1D5) were used as an outcome in MANCOVA. All calculated scores belonging to each of the 5 dimensions of COPSOQ were summed and the final sum score was used as a response variable representing each dimension in ANCOVA/MANCOVA.

Multivariate association between socioeconomic status and the psychosocial dimensions at work was confirmed by Wilks' Lambda test where all background factors were significant.

Suggested cut-off points for each dimension were produced. Values above the cut-off point for dimension $1 \mathrm{indi}-$ cated a bad situation, and vice versa for other dimensions.

A univariate comparison was done to confirm if there was an association between each dimension and all covariates. This means that comparisons did not take into account the effect of other dimensions. Our intention was to reject covariates (background and socioeconomics) that were not significant in both multivariate and univariate models.

An insubstantial relationship was observed between demographic and socioeconomic variables but it did not cause any multicollinearity problem, which was controlled by Variance Inflation Factors in the model (26, 27). The multivariate relationship between linear combinations of the set explanatory variables and D1-D5 was controlled by nonlinear canonical correlation analysis and an approximation suggested by a number of researchers 
(28-30) was used to confirm these associations. All demographic and socioeconomic variables used in the ANCOVA/MANCOVA models were categorized by the Sigmarestricted parameterization. Effective hypothesis decomposition in multivariate tests of significance was performed by Wilks' lambda criterion (31) followed by an Ftest where all covariates indicated a significant multivariate relation.

A multiple comparison (contrast test) involving \%SimTests macro with Bonferroni adjustments and PROC MULTTEST in SAS as suggested by Westfall was used to compare differences within job title, and partitioned analysis of least squares means (32). All estimated least squares means (LSM) and 95\% CI are presented in Table 3.

The final analysis included sum scored as a response variable in five dimensions (D1-D5) where all scores in each dimension were summed separately and the assumption of multivariate normality was confirmed. The multivariate analysis of variance and covariance (ANCOVA/MANCOVA) were used to determine multivariate and univariate relationships between all the five psychosocial dimensions at the same time by using these values for Sum Scored as outcome (D1 - D5) and background variables as explanatory variables. The results are presented as least squared mean (LSM $\pm \mathrm{SE}$ ) for both univariate and multivariate relationships. All the statistical analyses were performed using SAS 9.3 (SAS Institute Inc., Cary, NC).

\section{Results}

7,027 out of the 8,086 invited health care workers responded to the questionnaires, corresponding to a response rate of $79.8 \%$. Among these, 1,923 questionnaires were excluded due to excessive missing information and 5,253 completed questionnaires were analysed. Among these, 1,832 participants were male (36\%) and 3,303 were female (64\%). Demographic characteristics of the study population are presented in Table 1.

Quantitative measurements (mean and standard deviation) of the psychosocial work environment in 26 different scores are presented in Table 2. The scores for 'Danish national average', 'German all occupations', and 'German hospital workers' are also included for comparison. A difference in the mean values of more than 5 points was considered relevant.

\subsection{International Comparison}

In 17 of the 26 scores, the Iranian health care workers reported a bad situation compared to the other published references, such as the study on the Danish working population (Table 2 ). The scores with more than a 5-point difference included: quantitative demands, emotional demands, demands for hiding emotions, sensory demands, influence at work, possibilities for development, degree of freedom at work, meaning of work, role clarity, role conflicts, social support, social relations, insecurity at work, job satisfaction, general health, mental health, vitality, and behavioural stress.

There were no large differences between the Iranian and Danish study populations in 8 scores, including: cognitive demands, commitment to the work place, predictability, quality of leadership, sense of community, job satisfaction, somatic stress, and cognitive stress. In one scale, feedback at work, the Danish sample had a worse situation than Iranian health care workers did.

In the comparison between Iranian Health care workers and German hospital workers in the scores such as emotional demands, demands for hiding emotions, commitment to the work place and cognitive stress, Iranian health care workers had a better situation and less exposure. However, in other scores, such as possibilities for development, degree of freedom at work, meaning of work, role clarity, social support, social relations, insecurity at work, and general health, Iranian health care workers had a worse psychosocial working environment compared to the German hospital workers.

It is interesting that, compared to the German 'all occupation group', the German hospital workers have a better psychosocial working environment in terms of meaning of work, quality of leadership, social support, feedback at work, social relations, and insecurity at work, and only in emotional demands do they have a worse situation compared to other occupations.

\subsection{Comparisons Between Occupational Groups in Iran}

Comparing occupations within the health care settings, nurses had the least favorable psychosocial work environment (Table 3). In 13 scores (quantitative demands, emotional demands, demands for hiding emotions, sensory demands, role conflict, behavioral stress, somatic stress, cognitive stress, less influence at work, low degree of freedom at work, low commitment to the work place, and less job satisfaction), the nurses had lower values than the average mean for other occupations.

Compared to the average employees, physicians were more exposed to low quality of leadership, less social support, less degree of freedom at work, and low sense of community.

Compared to the average employees, health experts were more exposed to less meaning of work, less predictability, and less role clarity and the unskilled workers were more exposed to less possibility for development, less social relations, and more insecurity at work. 
Table 1. Demographic Characteristics of the Study Population ${ }^{\mathrm{a}}$

\begin{tabular}{|c|c|c|c|c|}
\hline & Total & Females & Males & PValue $^{\text {b }}$ \\
\hline Age group, y & & & & $<0.001$ \\
\hline Under 30 & $1543(30)$ & $1154(35)$ & $389(21)$ & \\
\hline Between 31 and 50 & $2835(55)$ & $1737(53)$ & $1098(60)$ & \\
\hline More than 51 & 740 (15) & $402(12)$ & $338(19)$ & \\
\hline Education & & & & $<0.001$ \\
\hline High school and less & $1886(36)$ & $806(25)$ & $1080(60)$ & \\
\hline Technician & $597(12)$ & $419(13)$ & $178(10)$ & \\
\hline Bachelor and MSc & $2263(45)$ & $1873(57)$ & $390(21)$ & \\
\hline $\mathrm{PhD}$ & $51(1)$ & $22(1)$ & $29(2)$ & \\
\hline Physician & $285(6)$ & $151(4)$ & $134(7)$ & \\
\hline Job Title & & & & $<0.001$ \\
\hline Physician & $277(6)$ & $143(5)$ & $134(7)$ & \\
\hline Nurse & $1205(24)$ & $963(30)$ & $242(14)$ & \\
\hline Health expert & $885(18)$ & $696(22)$ & $189(11)$ & \\
\hline Office worker & $1406(28)$ & $914(28)$ & $492(28)$ & \\
\hline Simple worker & $1207(24)$ & $491(15)$ & $716(40)$ & \\
\hline Shift work & & & & $<0.001$ \\
\hline Day shift & $3058(62)$ & $1986(62)$ & $1072(61)$ & \\
\hline Afternoon shift & $67(1)$ & $36(1)$ & $31(2)$ & \\
\hline Night shift & $239(5)$ & $143(4)$ & $96(5)$ & \\
\hline Two shifts & $489(10)$ & $317(10)$ & $172(10)$ & \\
\hline Three shifts & $653(13)$ & $417(13)$ & $236(14)$ & \\
\hline Not-fixed working hours & $395(8)$ & $282(9)$ & $113(6)$ & \\
\hline Others & $50(1)$ & $19(1)$ & $31(2)$ & \\
\hline Working hours, H/W & & & & $<0.001$ \\
\hline Full time 44 & $2558(52)$ & $1715(53)$ & $843(48)$ & \\
\hline Full time more than 44 & $1829(37)$ & $1086(34)$ & $743(42)$ & \\
\hline Part time $(20-40)$ & $577(11)$ & $405(13)$ & $172(10)$ & \\
\hline Income, mil Rials & & & & $<0.001$ \\
\hline Less than 5 & $3878(76)$ & $2592(78)$ & $1286(70)$ & \\
\hline Between 5 and 10 & $1124(21)$ & $660(20)$ & $464(25)$ & \\
\hline More than 10 & $133(3)$ & $51(2)$ & $82(5)$ & \\
\hline Work place & & & & $<0.001$ \\
\hline University campus & $847(17)$ & $437(14)$ & $410(23)$ & \\
\hline Hospital & $2831(57)$ & $1841(57)$ & $990(56)$ & \\
\hline District health office & $303(6)$ & $185(6)$ & $118(6)$ & \\
\hline Urban health center & $900(18)$ & $676(21)$ & $224(13)$ & \\
\hline Rural health center & $107(2)$ & $77(2)$ & $30(2)$ & \\
\hline
\end{tabular}

${ }^{\mathrm{a}}$ Values are expressed as No. (\%)

${ }^{\mathrm{b}}$ Chi-square test. 
Table 2. COPSOQ Context and Level of Dimensions $\mathrm{s}^{\mathrm{a}}$

\begin{tabular}{|c|c|c|c|c|c|c|}
\hline $\begin{array}{l}\text { Context and Level } \\
\text { of Dimensions }\end{array}$ & Scores & $\begin{array}{c}\text { Number of } \\
\text { Questions (Item) }\end{array}$ & Study Population & $\begin{array}{c}\text { German Hospital } \\
\text { Workers }\end{array}$ & $\begin{array}{l}\text { German All } \\
\text { Occupation }\end{array}$ & $\begin{array}{r}\text { Danish All } \\
\text { Occupation }\end{array}$ \\
\hline \multirow{5}{*}{$\begin{array}{l}\text { D1: Type of } \\
\text { production \& } \\
\text { tasks (Work place) }\end{array}$} & $\begin{array}{l}\text { 1. Quantitative } \\
\text { demands }\end{array}$ & 4 & $58(19)$ & $57(17)$ & $59(18)$ & $47(19)$ \\
\hline & $\begin{array}{l}\text { 2. Cognitive } \\
\text { demands }\end{array}$ & 4 & $63(18)$ & - & $63(21)$ & $63(21)$ \\
\hline & $\begin{array}{l}\text { 3. Emotional } \\
\text { demands }\end{array}$ & 3 & $54(28)$ & $64(19)$ & $58(20)$ & $38(25)$ \\
\hline & $\begin{array}{l}\text { 4. Demands for } \\
\text { hiding emotions }\end{array}$ & 2 & $44(25)$ & $51(21)$ & $48(22)$ & $30(23)$ \\
\hline & 5. Sensory demands & 4 & $73(19)$ & - & $62(23)$ & $62(23)$ \\
\hline \multirow{5}{*}{$\begin{array}{l}\text { D2: Work } \\
\text { organization \& } \\
\text { job content }\end{array}$} & 6. Influence at work & 4 & $44(20)$ & $41(20)$ & $45(22)$ & $55(24)$ \\
\hline & $\begin{array}{l}\text { 7. Possibilities for } \\
\text { development }\end{array}$ & 4 & $58(22)$ & $70(16)$ & $69(18)$ & $72(19)$ \\
\hline & $\begin{array}{l}\text { 8. Degree of } \\
\text { freedom at work }\end{array}$ & 4 & $28(18)$ & $42(18)$ & $44(24)$ & $65(25)$ \\
\hline & 9. Meaning of work & 3 & $71(18)$ & $82(16)$ & $77(18)$ & $78(16)$ \\
\hline & $\begin{array}{l}\text { 10. Commitment to } \\
\text { the work place }\end{array}$ & 4 & $61(22)$ & $56(19)$ & $56(20)$ & $57(21)$ \\
\hline \multirow{8}{*}{$\begin{array}{l}\text { D3: Interpersonal } \\
\text { relations \& } \\
\text { leadership }\end{array}$} & 11. Predictability & 2 & $56(21)$ & $55(21)$ & $51(23)$ & $60(23)$ \\
\hline & 12. Role clarity & 4 & $70(17)$ & $78(15)$ & $74(18)$ & $76(15)$ \\
\hline & 13. Role conflicts & 4 & $44(23)$ & $47(20)$ & $47(20)$ & $37(18)$ \\
\hline & $\begin{array}{l}\text { 14. Quality of } \\
\text { leadership }\end{array}$ & 4 & $58(25)$ & $55(25)$ & $47(26)$ & $55(21)$ \\
\hline & 15. Social Support & 4 & $50(22)$ & $70(20)$ & $63(21)$ & $68(20)$ \\
\hline & 16. Feedback at work & 2 & $44(25)$ & $45(21)$ & $39(23)$ & $39(23)$ \\
\hline & 17. Social relations & 2 & $52(20)$ & $70(20)$ & $45(28)$ & $68(30)$ \\
\hline & $\begin{array}{l}\text { 18. Sense of } \\
\text { community }\end{array}$ & 3 & $81(17)$ & $77(18)$ & $74(18)$ & $82(17)$ \\
\hline \multirow{2}{*}{$\begin{array}{l}\text { D4: } \\
\text { Work-individual } \\
\text { interface }\end{array}$} & $\begin{array}{l}\text { 19. Insecurity at } \\
\text { work }\end{array}$ & 4 & $39(36)$ & $33(22)$ & $26(22)$ & $17(25)$ \\
\hline & 20. Job satisfaction & 4 & $65(16)$ & $62(15)$ & $62(16)$ & $68(17)$ \\
\hline \multirow{6}{*}{$\begin{array}{l}\text { D5: Health and } \\
\text { well-being } \\
\text { (individual) }\end{array}$} & 21. General health & 5 & $53(11)$ & $73(18)$ & $73(18)$ & $81(17)$ \\
\hline & 22. Mental health & 5 & $35(10)$ & - & - & $79(15)$ \\
\hline & 23. Vitality & 4 & $41(11)$ & - & - & $64(19)$ \\
\hline & $\begin{array}{l}\text { 24. Behavioural } \\
\text { stress }\end{array}$ & 4 & $29(23)$ & - & - & $17(17)$ \\
\hline & 25. Somatic stress & 4 & $18(18)$ & - & - & $19(16)$ \\
\hline & 26. Cognitive stress & 4 & $22(21)$ & $28(18)$ & $28(19)$ & $20(18)$ \\
\hline
\end{tabular}

${ }^{\mathrm{a}}$ Values are expressed as mean (SD)

A multiple comparison adjustment using the Bonfer- 
Table 3. Age Adjusted Univariate Analysis of Covariate Based on Estimated Marginal Means and Standard Errors (SE) of COPSOQ Scores Among Different Job Titles in the Study Population

\begin{tabular}{|c|c|c|c|c|c|c|c|}
\hline \multirow[t]{2}{*}{ Context and Level } & \multirow[t]{2}{*}{ Scores } & \multicolumn{5}{|c|}{$\operatorname{Mean}(\mathrm{SE})^{\mathrm{a}}$} & \multirow[t]{2}{*}{ Univariate Test ${ }^{\mathrm{b}}$} \\
\hline & & Physician & Nurse & Health expert & office worker & Simple worker & \\
\hline \multirow{5}{*}{$\begin{array}{l}\text { D1: Type of production \& } \\
\text { tasks (Work place) }\end{array}$} & 1. Quantitative demands & $54.7(1.17)$ & $64.0(0.61)$ & $53.5(0.70)$ & $56.3(0.56)$ & $57.3(0.58)$ & $<0.01$ \\
\hline & 2. Cognitive demands & $69.9(1.06)$ & $69.0(0.55)$ & $60.9(0.63)$ & $62.0(0.50)$ & $57.9(0.53)$ & $<0.01$ \\
\hline & 3. Emotional demands & $59.8(1.79)$ & $69.8(0.82)$ & $53.1(0.94)$ & $42.3(0.74)$ & $48.0(0.78)$ & $<0.01$ \\
\hline & $\begin{array}{l}\text { 4. Demands for hiding } \\
\text { emotions }\end{array}$ & $45.9(1.48)$ & $51.7(0.78)$ & $42.8(0.88)$ & $38.5(0.70)$ & $42.2(0.74)$ & $<0.01$ \\
\hline & 5. Sensory demands & $75.6(1.18)$ & $81.4(0.62)$ & $71.4(0.71)$ & $68.6(0.57)$ & $69.3(0.59)$ & $<0.01$ \\
\hline \multirow{5}{*}{$\begin{array}{l}\text { D2: Work organization } \\
\text { \& job content }\end{array}$} & 6. Influence at work & $51.9(1.20)$ & $44.5(0.63)$ & $43.9(0.72)$ & $45.0(0.58)$ & $43.5(0.61)$ & $<0.01$ \\
\hline & $\begin{array}{l}\text { 7. Possibilities for } \\
\text { development }\end{array}$ & $71.5(1.29)$ & $64.2(0.68)$ & $60.3(0.77)$ & $57.0(0.61)$ & $51.7(0.64)$ & $<0.01$ \\
\hline & $\begin{array}{l}\text { 8. Degree of freedom at } \\
\text { work }\end{array}$ & $38.3(1.07)$ & $25.2(0.56)$ & $32.7(0.64)$ & $31.0(0.51)$ & $24.3(0.53)$ & $<0.01$ \\
\hline & 9. Meaning of work & $74.5(1.14)$ & $72.5(0.60)$ & $70.5(0.68)$ & $70.7(0.54)$ & $71.4(0.57)$ & $<0.01$ \\
\hline & $\begin{array}{l}\text { 10. Commitment to the } \\
\text { work place }\end{array}$ & $65.0(1.35)$ & $59.9(0.70)$ & $60.4(0.80)$ & $62.3(0.64)$ & $64.4(0.67)$ & $<0.01$ \\
\hline \multirow{8}{*}{$\begin{array}{l}\text { D3: Interpersonal } \\
\text { relations \& leadership }\end{array}$} & 11. Predictability & $55.9(21.7)$ & $56.4(20.8)$ & $54.1(19.7)$ & $56.1(21.4)$ & $58.1(22.4)$ & $<0.01$ \\
\hline & 12. Role clarity & $72.8(15.6)$ & $70.4(16.2)$ & $69.8(15.9)$ & $70.1(16.9)$ & $70.6(17.4)$ & 0.07 \\
\hline & 13. Role conflicts & $42.7(21.4)$ & $49.0(22.2)$ & $42.0(21.1)$ & $43.7(22.9)$ & $42.6(23.6)$ & $<0.01$ \\
\hline & 14. Quality of leadership & $54.1(24.0)$ & $55.5(24.8)$ & $54.1(24.4)$ & $58.0(25.3)$ & $64.6(25.3)$ & $<0.01$ \\
\hline & 15. Social Support & $48.7(20.8)$ & $51.0(21.6)$ & $50.4(20.4)$ & $49.3(22.7)$ & $51.5(23.9)$ & 0.06 \\
\hline & 16. Feedback at work & $40.3(22.5)$ & $43.7(24.2)$ & $41.2(23.4)$ & $41.7(25.3)$ & $49.9(27.3)$ & $<0.01$ \\
\hline & 17. Social relations & $56.8(19.6)$ & $49.1(18.6)$ & $51.9(18.9)$ & $52.7(20.8)$ & $51.1(22.1)$ & $<0.01$ \\
\hline & 18. Sense of community & $78.2(16.6)$ & $79.8(17.4)$ & $79.7(17.5)$ & $81.1(17.7)$ & $83.2(17.1)$ & $<0.01$ \\
\hline \multirow{2}{*}{$\begin{array}{l}\text { D4: Work-individual } \\
\text { interface }\end{array}$} & 19. Insecurity at work & $20.8(29.2)$ & $24.3(31.8)$ & $32.7(31.8)$ & $43.9(35.3)$ & $55.9(37.0)$ & $<0.01$ \\
\hline & 20. Job satisfaction & $66.7(13.9)$ & $61.2(16.3)$ & $63.6(15.9)$ & $65.6(15.9)$ & $66.9(17.6)$ & $<0.01$ \\
\hline \multirow{6}{*}{$\begin{array}{l}\text { D5: Health and } \\
\text { well-being (individual) }\end{array}$} & 21. General health & $52.2(9.1)$ & $52.1(10.4)$ & $52.5(10.0)$ & $52.8(10.5)$ & $53.6(11.9)$ & $<0.01$ \\
\hline & 22. Mental health & $36.0(8.4)$ & $36.1(10.0)$ & $35.9(9.4)$ & $35.2(9.6)$ & $34.6(10.9)$ & $<0.01$ \\
\hline & 23. Vitality & $41.0(10.1)$ & $40.9(11.2)$ & $40.4(10.7)$ & $40.1(10.8)$ & $40.9(12.9)$ & 0.33 \\
\hline & 24. Behavioural stress & $26.5(22.7)$ & $33.2(24.1)$ & $27.6(23.0)$ & $26.3(22.0)$ & $28.3(24.1)$ & $<0.01$ \\
\hline & 25. Somatic stress & $18.1(17.5)$ & $22.0(19.9)$ & $16.9(17.5)$ & $16.1(17.5)$ & $17.3(19.4)$ & $<0.01$ \\
\hline & 26. Cognitive stress & $24.8(20.3)$ & $25.8(21.5)$ & $22.2(19.7)$ & $20.3(19.4)$ & $20.8(21.1)$ & $<0.01$ \\
\hline
\end{tabular}

${ }^{a}$ All models are adjusted for Age and Gender.Main effect test value.

${ }^{\mathrm{b}}$ All univariate tests are adjusted for multiple comparison by Bonferroni adjustment.

roni method to adjust p-value was performed within job titles, age, and gender and the results are presented in Table 3. The final analysis included Sum Scored as a response variable in five dimensions (D1-D5) where all items in each dimension were summed separately (Table 4 and Figure 1 ).

The first dimension is type of production and tasks at work place (D1). The cut-off point is $290.92 \pm 5.36$ meaning that if the individual has a score greater that his value, he/she has a poor situation at work. Covariates associated with a poor situation were physicians, nurses, females, working more than 44 hours, self-rated health, and working at hospital. 
The second dimension is work organization and job content (D2) with a cut-off point of $285.92 \pm 5.12$. The covariates associated with a poor situation were older age, males, war history, self-rated health, and work at district health office or rural health center.

The third dimension is interpersonal relations and leadership (D5) with a cut-off point of $485.47 \pm 8.12$. The covariates associated with a poor situation were males, war history, excellent personal belief in general health, and working place at rural health center.

The fourth dimension has only two scores: insecurity at work and job satisfaction. The cut-off point for this dimension is $94.76 \pm 2.84$. Covariates associated with a poor situation were younger age, males, and excellent personal belief in general health. A negative association was found with the job title 'Nurses'.

The last dimension is health and well-being. The cutoff point for this dimension is $360.10 \pm 4.13$. We found a positive association between this dimension and job title as health expert and office worker, males, working hours of full time 44 hours, and self-rated health. These items could explain the health and well-being of Iranian health care workers.

\section{Discussion}

During the past three decades, Iran's population has doubled from 36 million to 75 million inhabitants and the number of hospital beds has increased from 57,000 beds to 110,000 beds. In addition, during this time the health network in the whole country has changed considerably. The number of health centers has increased from 4,000 to more than 17,000 urban and rural health facilities; this creates comprehensive access to primary and secondary health care services (33). Despite this, the number of jobs in the health care sector has not kept up with the population increase in recent years and a large number of highly educated people in health and medicine are seeking employment. Most of the new hospitals and clinics are run with insufficient human resources and this puts pressure on the health care employees. Aside from financial aspects, the psychosocial work environment can be one of the major factors driving the health care brain drain from Iran.

A few large studies have used the COPSOQ instrument and our results could only be compared with the German hospital workers and the Danish national average. Results from studies on the German hospital workers showed that, in some scores (possibilities for development, degree of freedom at work, meaning of work, role clarity, social support, social relations, insecurity at work, and general health), German hospital workers have a better psychosocial working environment compared to the Iranian health care workers. In contrast, the situation is the opposite for other scores (emotional demands, demands for hiding emotions, commitment to the work place, and cognitive stress) where German hospital workers are facing a worse psychosocial working environment compared to the Iranian health care workers.

This comparison reveals that the Iran health care system needs to pay more attention to work organization and job content, interpersonal relations and leadership, as well as the health and well-being of employees. One possible mechanism that could explain the difference in these scores involves the role of strong unions in negotiation and creating a better working environment for employees. This role is well defined in developed countries, which have more experience in this field. In addition, social factors such as financial situation and high unemployment rate play important roles. A challenging financial situation combined with a high unemployment rate restricts the possibility of raising these issues. In this situation, keeping one's current job as well as production rate are the most important issues for both employers and employees, making it difficult to improve the psychosocial work environment.

Compared to the Danish national average in terms of the scores of the 26 scores in COPSOQ, the psychosocial exposures of Iranian health care workers are significantly higher (more than 5 points difference in each scale's mean) in at least 16 scores, and in only one scale (feedback at work) the Iranian health care workers have less exposure. Most demands on the health care workers included in this study are high. One possible explanation for the difference between the Iranian and Danish groups could be the volume of the patients and shortage of health care personnel in hospitals and clinics. This is an important issue for those driving future health care policies. The total health care system in Iran is under expansion and the volume of end-users requiring health care services is increasing, with changes in the population pyramid and aging population.

Comparing the scores for the 26 scores in COPSOQ between the occupational groups indicated that nurses had significantly higher scores in most scores. This is not surprising considering that there is a severe shortage of nurses in Iran, which is a cause of great concern that can explain the high level of 'intention to leave job' among nurses.

The terminology of 'Nursing shortage' is usually defined as the gap between the number of available nurses and the optimum number of nurses (34). The nurse-topopulation ratio in USA is 700:10,000 while in Uganda this ratio is $6: 10,000$. Both countries have reported a nursing shortage (34), indicating that the context of shortage is defined by each country's national structure for health care 

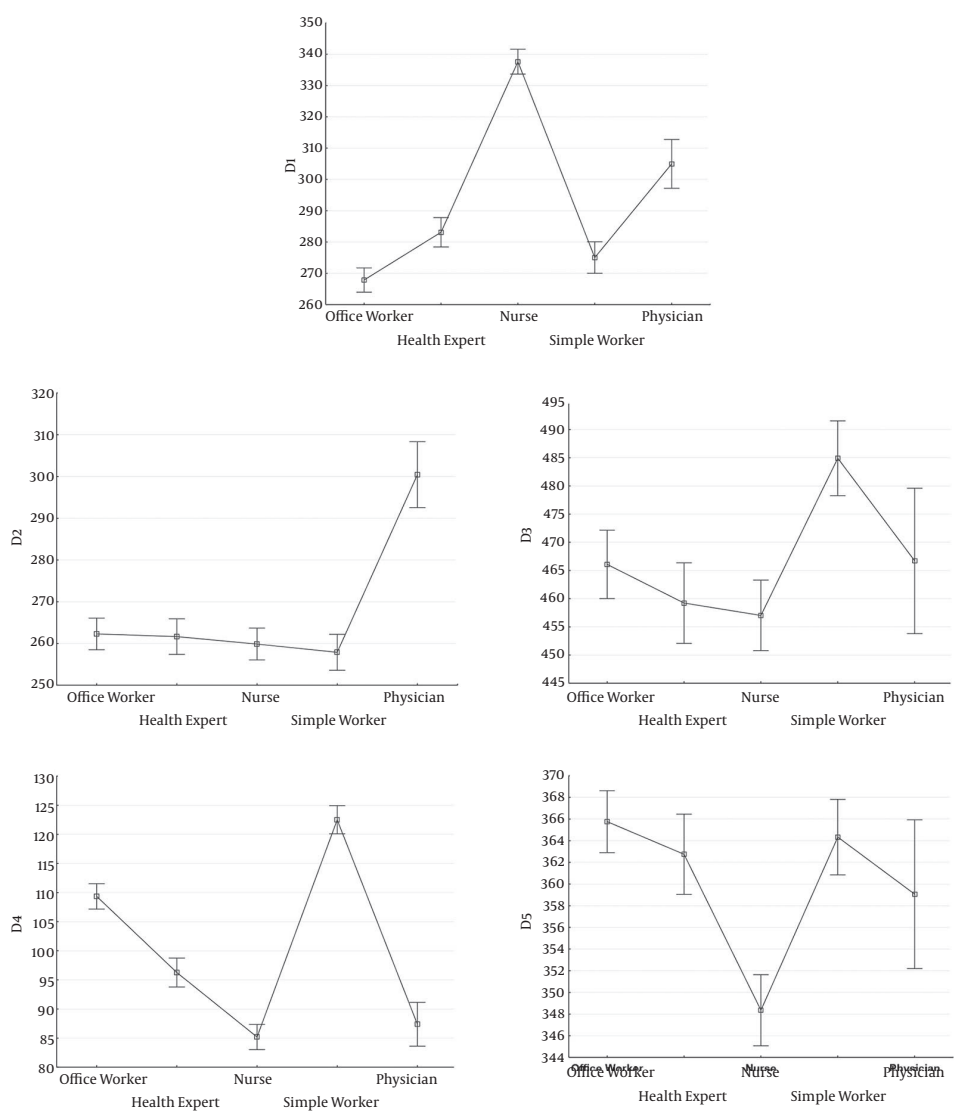

Error bars represent the 95\% confidence Interval for Mean. D1, Type of production \& tasks(work place); D2, Working organization \& job content; D3, Interpersonal relation \& leadership; D4, Work-individual interface; D5, Health and well-being(individual); Job titles: Office worker, health expert, Nurse, Simple worker, Physician

personnel. A study in Iran in 2009 estimated that there were 90,026 nurses in Iran, but hospitals and health-care facilities need around 220,000 nurses in order to deliver optimal nursing care and services (35).

The average density of nurses per 1,000 citizens throughout the world is 4.06, whereas the density of nurses in Iran is 1.31 (36). The results from a study in 2010 indicated that high emotional demands, low meaning of work, low commitment to the workplace, and low job satisfaction were constantly predictive factors for nurses intending to leave their job (37). In a study among the European nurses, the three most important factors strongly associated with nurses' intention to leave were poor professional opportunities, unpleasant work organization, and low health status (38). Another study from Sweden found that an unsatisfactory salary contributed most to the nurse's decision to leave (39). One study on nurses in the UK suggested that work environment-related factors rather than individual or demographic factors were still of most importance to the turnover in nurses and their intention to leave (40).

Findings from an Iranian study (41) about perceptions of nursing practices in Iran showed that Iranian nurses operate in undesirable working conditions. Most of them are overworked and underpaid compared to other professions with a similar level of knowledge and expertise. They also found that the nurses feel that they are forced to put more effort into administrative duties rather than they focus on the patient's needs.

Nurses comprise the main group of health care employees in Iran and they provide a significant portion of patient care; but they do not enjoy the same status in healthcare organizations as others, especially physicians (42). The consequences can be dissatisfaction, lack of motivation, and low quality of service among nurses, all of which leading to patient dissatisfaction $(42,43)$. Our results support the results of previous studies and confirm the poor psychosocial environment among nurses. 
In total, the psychosocial factors at work in our study are favourable for office workers and unskilled workers when compared to the other groups. In contrast, those working directly with patients and providing health services are exposed to more negative psychosocial factors.

The vast majority of our study population was female, as was also the case for the health care system in Iran. Women are the main health care providers at different levels, from small health houses in the villages to the big hospitals in major cities (33). The proportion of female health care workers has increased, not only in Iran but also in most Western countries. This is also the situation for females in higher medical positions, who have increased to over $50 \%$ in the last 20 years in Germany (5).

We can find significant gender differences by comparing the means of the psychosocial factors at work in our study. Women have a significantly worse situation compared to men in four of five dimensions of the psychosocial factors at work. Gender differences have also been reported in other studies $(23,44,45)$. Women dominate the health care system in Iran and other countries, making this gender difference an important issue. Male experts hold most of the managerial positions in the health care system, and improving the psychosocial work environment needs their serious attention.

All previous studies using the COPSOQ instrument have focused on analyzing the scores introduced in the instrument. Kristiensen introduced five dimensions into the COPSOQ based on the different scores, but these dimensions have not been analyzed in many studies. Our approach places more attention on five dimensions, creating a sum score for each dimension and provides an advanced analysis of COPSOQ.

Our study adds to prior research about the health of health care workers by a broader mapping of the psychosocial work environment among health care workers in Iran rather than an inventory with a specific focus on stress or burnout.

This study had some additional strengths as well as limitations. Large samples of health care workers in different occupational groups from different centers create a comprehensive resource for analysis. Moreover, using a standard validated tool to measure the psychosocial working environment among health care workers is another strength in this study. Comparing our study population with populations in Germany and Denmark reported by previous studies shows a good external validity, which in turn indicates a possible generalization of our results in this paper. On the other hand, the study is limited by cross-sectional design as well as some dropouts and uncompleted questionnaires apart from the self-reported exposures.
Surveying within a single special occupational group (health care workers) has both advantages and disadvantages, since it creates less variation in the traditional psychosocial risk factors, as the workers experience the same working conditions. The traditional domains of psychosocial factors, such as quantitative demands and influence, are work factors that are much more related to job type rather than to work environment and place of work. On the other hand, some domains, such as leadership quality and predictability, are more dependent on the place of work and work environment rather than to job type. Our study design is also well adapted to detect the factors related to the place of work.

\subsection{Conclusions}

The present study on the psychosocial work environment of Iranian health care workers reveals that health care workers experience substantial adverse psychosocial exposures. Our study also showed significant differences in the psychosocial work environment among occupational groups in health care. Nurses had significantly higher scores in most scores. The significant gender difference and the important role of female employees in the Iranian health care system indicate that management should place more focus on improving the psychosocial work environment of the health care system in Iran.

- What this paper adds

- Healthcare professionals worldwide are exposed to a complex variety of psychosocial factors. The purpose of this study is to describe the psychosocial status of the healthcare workers in Iran and its association with socioeconomic status.

- COPSOQ is one of the validated tools for measuring psychosocial occupational exposure. The questionnaire was developed in three versions (long, medium, and short) and its long version includes 30 scores of work and health using 141 items. The medium version of COPSOQ with 26 scores and 94 items was used in this study to evaluate the psychosocial work environment among healthcare workers and its association with work and socioeconomic status.

- All previous studies using COPSOQ instrument focused on analyzing the scores established into the instrument. The origin dimensions in COPSOQ are based on the different scores, but these dimensions have not been analyzed in previous studies. Our approach pays more attention to these dimensions, creating a new score for each dimension and providing an advanced analysis of COPSOQ. This in turn provides a cutoff point for each dimension and makes it easier for future studies to be compared with meta-analysis. 


\section{References}

1. Hongoro $\mathrm{C}$, McPake $\mathrm{B}$. How to bridge the gap in human resources for health. Lancet. 2004;364(9443):1451-6. doi:10.1016/S01406736(04)17229-2. [PubMed: 15488222].

2. WHO . Chapter 4 - Selected occupational risks. ; 2004.

3. WHO . Migration of Health Care Workers. ; 2010.

4. Serdar T, Derek L, Unic A, Marijancevic D, Markovic D, Primorac A, et al. Occupational exposures in healthcare workers in University Hospital Dubrava-10 year follow-up study. Cent Eur I Public Health. 2013;21(3):150-4. [PubMed: 24344541].

5. Fuss I, Nubling M, Hasselhorn HM, Schwappach D, Rieger MA. Working conditions and Work-Family Conflict in German hospital physicians: psychosocial and organisational predictors and consequences. BMC Public Health. 2008;8:353. doi: 10.1186/1471-2458-8-353. [PubMed: 18840296].

6. Chou LP, Li CY, Hu SC. Job stress and burnout in hospital employees: comparisons of different medical professions in a regional hospital in Taiwan. BMJ Open. 2014;4(2):e004185. doi: 10.1136/bmjopen-2013004185.

7. Kovner CT, Brewer CS, Fatehi F, Jun J. What does nurse turnover rate mean and what is the rate? Policy Politics Nurs Pract. 2014;15(3-4):6471.

8. Vingard E, Alfredsson L, Hagberg M, Kilbom A, Theorell T, Waldenstrom $\mathrm{M}$, et al. To what extent do current and past physical and psychosocial occupational factors explain care-seeking for low back pain in a working population? Results from the Musculoskeletal Intervention Center-Norrtalje Study. Spine (Phila Pa 1976). 2000;25(4):493-500. [PubMed: 10707397].

9. Lohela M, Bjorklund C, Vingard E, Hagberg J, Jensen I. Does a change in psychosocial work factors lead to a change in employee health? J Occup Environ Med. 2009;51(2):195-203. doi: 10.1097/JOM.ob013e318192bd2c. [PubMed: 19209041].

10. Kristensen TS, Hannerz H, Hogh A, Borg V. The Copenhagen Psychosocial Questionnaire-a tool for the assessment and improvement of the psychosocial work environment. Scand J Work Environ Health. 2005;31(6):438-49. [PubMed: 16425585].

11. Ghaffari M, Alipour A, Farshad AA, Jensen I, Josephson M, Vingard E. Effect of psychosocial factors on low back pain in industrial workers. Occup Med (Lond). 2008;58(5):341-7. doi:10.1093/occmed/kqno06. [PubMed: 18296687].

12. Vaez M, Josephson M, Vingard E, Voss M. Work-related violence and its association with self-rated general health among public sector employees in Sweden. Work. 2014;49(1):163-71. doi: 10.3233/WOR-131715. [PubMed: 24004771].

13. Haladay DE, Blorstad AL, McBrier NM, Denegar CR, Lengerich EJ. Back pain among health care workers in Pennsylvania 2002-2006. Work. 2012;41(1):93-8. doi: 10.3233/WOR-2012-1288. [PubMed: 22246309].

14. Nayeri ND, Salehi T, Noghabi AA. Quality of work life and productivity among Iranian nurses. Contemp Nurse. 2011;39(1):106-18. doi: 10.5172/conu.2011.39.1.106. [PubMed: 21955271].

15. McKevitt C, Morgan M, Dundas R, Holland WW. Sickness absence and 'working through' illness: a comparison of two professional groups. J Public Health Med. 1997;19(3):295-300. [PubMed: 9347453].

16. Rosvold EO, Bjertness E. Physicians who do not take sick leave: hazardous heroes? Scandinavian J Soc Med. 2001;29(1):71-5.

17. Rabin S, Feldman D, Kaplan Z. Stress and intervention strategies in mental health professionals. Br J Med Psychol. 1999;72 ( Pt 2):159-69. [PubMed: 10397421].

18. Attridge M. A quiet crisis: The business case for managing employee mental health. Human Solutions; 2008

19. Stansfeld S, Candy B. Psychosocial work environment and mental health-a meta-analytic review. Scand J Work Environ Health. 2006;32(6):443-62. [PubMed: 17173201].

20. Kivimaki M, Virtanen M, Elovainio M, Kouvonen A, Vaananen A Vahtera J. Work stress in the etiology of coronary heart disease- a meta-analysis. Scand J Work Environ Health. 2006;32(6):431-42. [PubMed: 17173200].

21. Belkic K, Schnall P, Landsbergis P, Baker D. The workplace and cardiovascular health: conclusions and thoughts for a future agenda. Occup Med. 2000;15(1):307-21. [PubMed:10702092] v-vi.

22. Moncada S, Pejtersen JH, Navarro A, Llorens C, Burr H, Hasle P, et al. Psychosocial work environment and its association with socioeconomic status. A comparison of Spain and Denmark. Scand J Public Health. 2010;38(3 Suppl):137-48. doi: 10.1177/1403494809353825. [PubMed: 21172779].

23. Nubling M, Stossel U, Hasselhorn HM, Michaelis M, Hofmann F. Measuring psychological stress and strain at work - Evaluation of the COPSOQ Questionnaire in Germany. Psychosoc Med. 2006;3:Doc05. [PubMed: 19742072].

24. Arsalani N, Fallahi-Khoshknab M, Josephson M, Lagerstrom M. Iranian nursing staff's self-reported general and mental health related to working conditions and family situation. Int Nurs Rev. 2012;59(3):416-23. doi: 10.1111/j.1466-7657.2012.00987.x. [PubMed: 22897195].

25. Kristensen TS. A new tool for assessing psychosocial factors at work: The Copenhagen Psychosocial Questionnaire. Copenhagen: National Institute of Health; 2000.

26. Belsley DA, Kuh E, Welsch RE. Regression diagnostics: Identifying in fluential data and sources of collinearity. John Wiley \& Sons; 2005.

27. Ramsey JB. Tests for specification errors in classical linear leastsquares regression analysis. J Royal Statistic Soc. 1969:350-71.

28. Hotelling H. Relations between two sets of variates. Biometrika. 1936;28(3/4):321-77.

29. Rao CR. Linear statistical inference and its applications, second Edition. Statistics WSiPa. New York: John Wiley \& Sons; 1973.

30. Kshirsagar AM. Multivariate Analysis, New York: MarcelDekker. New York: Marcel Dekker; 1972.

31. Wilks SS. Certain generalizations in the analysis of variance. Biometrika. 1932:471-94.

32. Westfall PH, Young SS. Resampling-based multiple testing: Examples and methods for p-value adjustment. 279. John Wiley \& Sons; 1993.

33. Iran National statistics . Iran National statistics book. Iran: Ministry of Health statistics; 2004.

34. Buchan J. Evidence of nursing shortages or a shortage of evidence? J Adv Nurs. 2006;56(5):457-8. doi: 10.1111/j.1365-2648.2006.04072_2.x. [PubMed: 17078821].

35. Zarea K, Negarandeh R, Dehghan-Nayeri N, Rezaei-Adaryani M Nursing staff shortages and job satisfaction in Iran: issues and challenges. Nurs Health Sci. 2009;11(3):326-31. doi: 10.1111/j.1442 2018.2009.00466.x. [PubMed: 19689643].

36. World Health Organization . The world health report 2006: working together for health. World Health Organization; 2006.

37. Li J, Fu H, Hu Y, Shang L, Wu Y, Kristensen TS, et al. Psychosocial work environment and intention to leave the nursing profession: results from the longitudinal Chinese NEXT study. Scand J Public Health. 2010;38(3 Suppl):69-80. doi: 10.1177/1403494809354361. [PubMed: 21172773].

38. Hasselhorn HM, Tackenberg P, Kuemmerling A, Wittenberg J, Simon M, Conway PM, et al. Nurses' health, age and the wish to leave the profession-findings from the European NEXT-Study. Med Lav. 2006;97(2):207-14. [PubMed:17017351].

39. Fochsen G, Sjogren K, Josephson M, Lagerstrom M. Factors contributing to the decision to leave nursing care: a study among Swedish nursing personnel.J Nurs Manag. 2005;13(4):338-44. doi:10.1111/j.13652934.2005.00546.x. [PubMed: 15946173].

40. Coomber B, Barriball KL. Impact of job satisfaction components on intent to leave and turnover for hospital-based nurses: a review of the research literature. Int J Nurs Stud. 2007;44(2):297-314. doi: 10.1016/j.ijnurstu.2006.02.004. [PubMed:16631760]. 
41. Nikbakht Nasrabadi A, Emami A. Perceptions of nursing practice in Iran. Nurs Outlook. 2006;54(6):320-7. doi: 10.1016/j.outlook.2006.06.001. [PubMed: 17142150].

42. Rahimaghaee F, Nayeri D, Mohammadi E. Iranian nurses perceptions of their professional growth and development. Online J Issues Nurs. 2011;16(1):10.

43. Dehghan Nayeri N, Nazari AA, Salsali M, Ahmadi F, Adib Hajbaghery M. Iranian staff nurses' views of their productivity and management factors improving and impeding it: a qualitative study. Nurs Health Sci. 2006;8(1):51-6. doi: 10.1111/j.1442-2018.2006.00254.x.
[PubMed: 16451429].

44. Andreassen $\mathrm{CN}$, Eriksen JG. The psychosocial work environment among physicians employed at Danish oncology departments in 2009. A nationwide cross-sectional study. Acta Oncol. 2013;52(1):13846. doi: 10.3109/0284186X.2012.702926. [PubMed: 23033812].

45. Hooftman WE, van der Beek AJ, Bongers PM, van Mechelen W. Is there a gender difference in the effect of work-related physical and psychosocial risk factors on musculoskeletal symptoms and related sickness absence? Scandinavian J Work Environ Health. 2009;35(2):85-95. doi: 10.5271/sjweh.1316. 
Table 4. Univariate and Multivariate Tests of Significance for Each Dimension of COPSOQ; Sigma-Restricted Parameterization and Effective Hypothesis Decomposition of All Background Variables in Association with Each Dimension of COPSOQ are Presented by LS-Means and SE (LS-Means \pm SE)

\begin{tabular}{|c|c|c|c|c|c|c|c|c|c|c|c|c|c|}
\hline & & \multicolumn{10}{|c|}{ Univariate Analysis of Variance and Covariance (LS-Means \pm SE) ${ }^{\mathbf{a}}$} & \multicolumn{2}{|c|}{ Multivariate Analysis } \\
\hline & & $\begin{array}{c}\text { D1- Type of } \\
\text { Production } \\
\text { and Tasks } \\
\text { (Work Place) }\end{array}$ & PValue & $\begin{array}{l}\text { D2-Work } \\
\text { Organization } \\
\text { and Job } \\
\text { Content }\end{array}$ & PValue & $\begin{array}{c}\text { D3- } \\
\text { Interpersonal } \\
\text { Relations \& } \\
\text { Leadership }\end{array}$ & PValue & $\begin{array}{l}\text { D4-Work- } \\
\text { Individual } \\
\text { Interface }\end{array}$ & PValue & $\begin{array}{l}\text { D5-Health } \\
\text { and } \\
\text { Well-Being } \\
\text { (Individual) }\end{array}$ & Pvalue & $\begin{array}{l}\text { Multivariate } \\
\text { Tests (Wilks } \\
\text { Lambda) }\end{array}$ & $\begin{array}{c}\text { Partial } \\
\text { Eta-Squared } \\
\text { (Effect Size) }\end{array}$ \\
\hline & & & & & & & & & & & & PValue & \\
\hline $\begin{array}{l}\text { Overall m } \\
\text { (Suggestec } \\
\text { cut-off } \\
\text { point })^{\mathbf{c}}\end{array}$ & $\begin{array}{l}\text { nean } \\
\text { ed }\end{array}$ & $290.92 \pm 5.36$ & & $285.92 \pm 5.12$ & & $485.47 \pm 8.12$ & & $94.76 \pm 2.84$ & & $360.10 \pm 4.13$ & & & \\
\hline \multirow[t]{4}{*}{ Age } & & & 0.18 & & $<0.01$ & & 0.80 & & $<0.01$ & & 0.40 & $<0.01$ & 0.010 \\
\hline & $\begin{array}{l}1 \\
\text { Equal } \\
\text { or } \\
\text { less } \\
\text { than } \\
\text { 30(Ref) }\end{array}$ & $287.53 \pm 5.81$ & & $279.45 \pm 5.55$ & & $486.85 \pm 8.79$ & & $100.58 \pm 3.07$ & & $362.02 \pm 4.47$ & & & \\
\hline & $\begin{array}{l}2 \text { Be- } \\
\text { tween } \\
\text { 3land } \\
50\end{array}$ & $292.92 \pm 5.38$ & & $284.66 \pm 5.15$ & & $483.99 \pm 8.16$ & & $91.55 \pm 2.85$ & & $359.04 \pm 4.15$ & & & \\
\hline & $\begin{array}{l}3 \\
\text { Equal } \\
\text { or } \\
\text { more } \\
\text { than } \\
51\end{array}$ & $292.29 \pm 6.18$ & & $293.65 \pm 5.91$ & & $485.56 \pm 9.16$ & & $92.12 \pm 3.27$ & & $359.22 \pm 4.77$ & & & \\
\hline \multirow{5}{*}{ Job title } & & & $<0.01$ & & 0.31 & & 0.28 & & $<0.01$ & & $<0.01$ & $<0.01$ & 0.025 \\
\hline & $\begin{array}{l}1 \\
\text { Physi- } \\
\text { cian(Ref) }\end{array}$ & $300.95 \pm 8.02$ & & $292.71 \pm 7.66$ & & $480.36 \pm 12.15$ & & $100.80 \pm 4.23$ & & $354.13 \pm 6.18$ & & & \\
\hline & 2 & $317.70 \pm 3.48$ & & $287.17 \pm 6.20$ & & $482.89 \pm 9.82$ & & $81.23 \pm 3.43$ & & $355.20 \pm 5.00$ & & & \\
\hline & $\begin{array}{l}3 \\
\text { Health } \\
\text { Ex- } \\
\text { pert }\end{array}$ & $280.29 \pm 6.70$ & & $286.67 \pm 6.40$ & & $484.60 \pm 10.15$ & & $93.68 \pm 3.54$ & & $365.91 \pm 5.17$ & & & \\
\hline & $\begin{array}{l}4 \text { Of- } \\
\text { fice } \\
\text { Worker }\end{array}$ & $272.71 \pm 6.68$ & & $283.98 \pm 6.39$ & & $483.66 \pm 10.13$ & & $97.70 \pm 3.54$ & & $365.34 \pm 5.16$ & & & \\
\hline \multirow[t]{3}{*}{ Gender } & & & 0.14 & & $<0.01$ & & 0.05 & & $<0.01$ & & $<0.01$ & $<0.01$ & 0.019 \\
\hline & $\begin{array}{l}1 \\
\text { Women(ref }\end{array}$ & f) $293.12 \pm 5.65$ & & $281.23 \pm 5.41$ & & $481.06 \pm 8.57$ & & $91.95 \pm 2.99$ & & $352.47 \pm 4.36$ & & & \\
\hline & $\begin{array}{l}2 \\
\text { Men }\end{array}$ & $288.71 \pm 5.47$ & & $290.61 \pm 5.23$ & & $489.87 \pm 8.29$ & & $97.56 \pm 2.89$ & & $367.72 \pm 4.22$ & & & \\
\hline \multicolumn{2}{|l|}{ Shift Work } & & $<0.01$ & & 0.11 & & 0.19 & & 0.48 & & 0.13 & $<0.01$ & 0.007 \\
\hline & $\begin{array}{l}1 \text { Day } \\
\text { Time } \\
\text { (Ref) }\end{array}$ & $275.49 \pm 4.53$ & & $290.61 \pm 4.34$ & & $487.19 \pm 6.87$ & & $97.61 \pm 2.40$ & & $362.63 \pm 3.50$ & & & \\
\hline & $\begin{array}{l}4 \\
\text { Two } \\
\text { Shifts }\end{array}$ & $294.37 \pm 5.89$ & & $289.89 \pm 5.63$ & & $491.53 \pm 8.93$ & & $96.31 \pm 3.12$ & & $359.77 \pm 4.54$ & & & \\
\hline & $\begin{array}{l}5 \\
\text { Three } \\
\text { Shifts }\end{array}$ & $294.37 \pm 5.76$ & & $284.69 \pm 5.50$ & & $485.30 \pm 8.73$ & & $93.11 \pm 3.04$ & & $363.61 \pm 4.44$ & & & \\
\hline \multirow[t]{3}{*}{$\begin{array}{l}\text { Working } \\
\text { Hours }\end{array}$} & & & $<0.01$ & & 0.35 & & 0.34 & & $<0.01$ & & 0.06 & $<0.01$ & 0.007 \\
\hline & $\begin{array}{l}1 \text { Full } \\
\text { time } \\
44 \mathrm{H} / \text { wet } \\
\text { (Ref) }\end{array}$ & $290.30 \pm 5.52$ & & $288.42 \pm 5.28$ & & $484.37 \pm 8.37$ & & $91.31 \pm 2.92$ & & $362.42 \pm 4.26$ & & & \\
\hline & $\begin{array}{l}2 \\
\text { Full } \\
\text { time } \\
\text { more } \\
\text { than } \\
44 \mathrm{H} / \mathrm{W}\end{array}$ & $299.20 \pm 5.53$ & & $286.50 \pm 5.29$ & & $481.17 \pm 8.38$ & & $92.48 \pm 2.93$ & & $357.17 \pm 4.27$ & & & \\
\hline
\end{tabular}




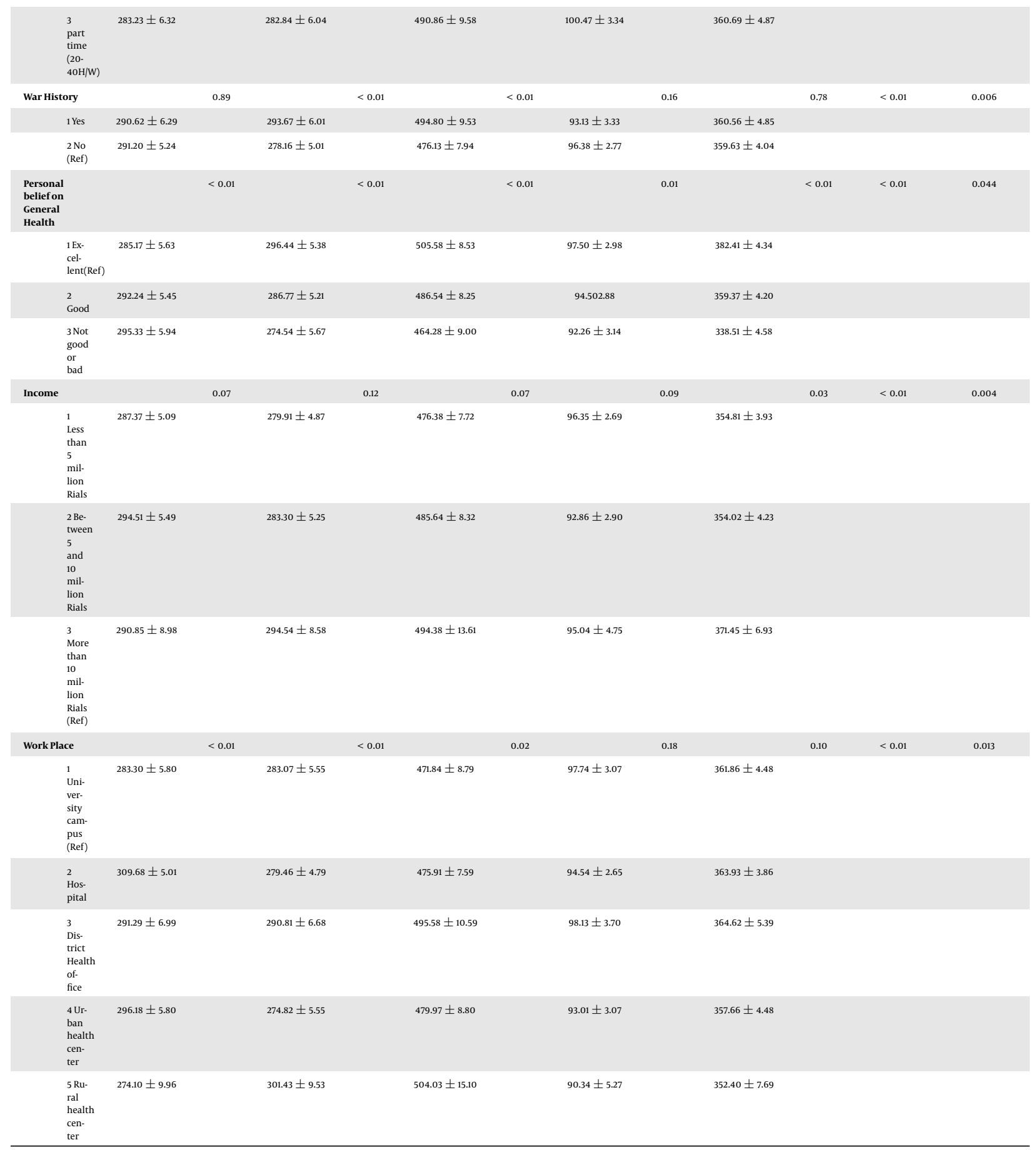

Abbreviation: LS-mean: least square mean

${ }^{a}$ Main effect test value. All univariate tests are adjusted for multiple comparisons by Tuky-Kramer adjustment.

' ${ }^{\text {Statistic multivariate analyses of variance are Wilks' Lambda. }}$

${ }^{\mathrm{C}}$ Overall mean: Indicating intercept from ANOVA/ANCOVA model that is equal to an overall mean of each dimension in the study population. 